\title{
Pattern of drug prescription for the treatment of falciparum malaria in a medical college in Eastern India
}

\author{
Pratyay Pratim Datta', Anju Prasad², Chaitali Pattanayak², Ashok Singh Chouhan ${ }^{3}$, \\ Parbaty Panda ${ }^{4}$ \\ ${ }^{1}$ Assistant Professor, Department of Pharmacology, Gouri Devi Institute of Medical Sciences, Durgapur, West Bengal, \\ India, ${ }^{2}$ Associate Professor, ${ }^{3}$ Tutor, ${ }^{4}$ Professor \& Head, Department of Pharmacology, Hi-Tech Medical College, \\ Bhubaneswar, India.
}

Background: Drug prescription pattern for the treatment of falciparum malaria differs widely from place to place; but there is also some intra organizational variation of prescription pattern of anti-malarial drugs for the treatment of falciparum malaria. Aims and Objectives: The present study was planned to study the drug utilization pattern for the treatment of falciparum malaria in a tertiary care teaching hospital in eastern India. Materials and Methods: It was a hospital based study conducted in the department of medicine among the patients admitted with confirmed diagnosis of falciparum malaria. Drugs prescribed, average number of drugs per prescription, percentage of drugs prescribed in generic name, percentage of prescription with co-prescription of antibiotics, percentage of prescription having at least an injection prescribed, percentage of drugs prescribed from essential drug list or formulary and average drug cost per prescription are the parameters studied in this study. Results: Average number of drugs per prescription in the present study was 3.96. Artesunate and Mefloquine were the most common anti-malarial drugs prescribed among study subjects. $22.9 \%$ patients received oral Chloroquine as anti-malarial drug. $43.3 \%$ prescriptions had antibiotics co-prescribed. Only $16.9 \%$ drugs were prescribed in generic name. $85.4 \%$ of the prescribed drugs were from essential drug list. Average drug cost per patient was Rs. 282/- with minimum of Rs. 55/- and maximum of Rs. 1750/-. Conclusion: Though Artesunate combination therapy is getting popularized gradually but a sizable proportion of patients $(22.9 \%)$ were prescribed with oral Chloroquine therapy. Generic prescription of drugs should be encouraged among the physicians. Multi-centric study regarding drug prescription can give a broader picture in changing scenario.

\section{Access this article online}

Website:

http://nepjol.info/index.php/AJMS DOI: 10.3126/ajms.v7i4.14614 E-ISSN: 2091-0576

P-ISSN: $2467-9100$

Key words: Falciparum malaria, Drug prescription pattern, Generic name, Essential drug list, Drug cost

\section{INTRODUCTION}

Falciparum malaria is one of the most serious diseases in endemic areas. It is sure that there is wide variation of incidence of falciparum malaria from place to place. There are many factors associated with its incidence. With the changing climatological and sociological variation across the world, there is change in proportion of type of malaria with gradual increase in proportion of falciparum malaria and decrease in proportion of vivax malaria. The continuous development of resistance of malaria parasite against different anti-malarial drugs has forced scientists to develop new and new anti-malarial drugs with different mechanism of action and different level of attack on malaria parasite. The sensitivity of Plasmodium falciparum varies from place to place. Based on the sensitivity of the parasite there is change in the drug prescription pattern from place to place. But, the prescription pattern also changes according to patient characteristics and prescriber characteristics. Drug utilization research was defined by 
WHO in 1977 as "the marketing, distribution, prescription and use of drugs in a society, with special emphasis on the resulting medical, social and economic consequences". 1 The present study was conducted in a medical college hospital of Odisha, India about the drug prescription pattern for the treatment of falciparum malaria.

\section{MATERIALS AND METHODS}

The study was conducted in a medical college of Bhubaneswar, Odisha, India. It was a hospital based cross sectional study conducted in medicine department of Hi-Tech Medical College, Odisha, India. The study was conducted from January, 2012 to December, 2013. The study was conducted among the patients admitted in the department of medicine with confirmed diagnosis of falciparum malaria. The prescriptions issued for these patients at the time of admission were taken and assessed for the following parameters:

a. Average no. of drugs per prescription

b. Percentage of drugs prescribed in generic name

c. Percentage of prescription with antibiotic coprescribed

d. Percentage of prescription having at least an injection prescribed

e. Percentage of drugs prescribed from essential drug list or formulary

f. Average drug cost per prescription.

In addition to these, the patient characteristics and prescriber characteristics were also considered.

\section{RESULTS}

Most common anti-malarial drug combination prescribed was Artesunate with Mefloquine (26\%) in the study participants. Only oral chloroquine was prescribed to a good proportion of patients (23.1\%). Most of the patients were treated with oral drugs; only $6.7 \%$ patients received injectable anti-malarial drug (injectable Artemether) (Table 1).

It was found that total drugs prescribed for treating 208 patients was 824 and so the average number of drugs per patient was 3.96. Out of artemisinin drugs Artesunate was the most commonly prescribed one which was prescribed to $48.1 \%$ patients. Primaquine was prescribed to $56.7 \%$ patients. Out of non-anti-malarial drugs, most commonly prescribed was proton pump inhibitor $(65.4 \%$ patients) (Table 2).

It was found that overall only $16.9 \%$ drugs were prescribed in generic name. $\mathrm{H}_{2}$ blockers were most commonly prescribed in generic name (65.4\%) followed by Cefixime $(35.7 \%)$ and Amoxicillin (27.8\%). Out of anti-malarial drugs, Chloroquine was most commonly prescribed in generic name $(22.9 \%)$ (Table 3$)$.

Cost of the treatment varied widely among the study subjects. The minimum cost became Rs. 55/- for those who received oral chloroquine with least other medicine. The ACTs are costlier than Chloroquine and injectable drugs have still higher cost. Other drugs along with injectable Artemether in complicated malaria ultimately raised the cost of treatment to much higher level and the maximum direct medicine cost became Rs. 1750.00 (Table 6).

\section{DISCUSSION}

The present study has highlighted the drug utilization pattern for the treatment of falciparum malaria in a tertiary care teaching hospital in Bhubaneswar, India.

Very limited studies have been done on the drug utilization of falciparum malaria. In a study by Chedi BAZ et al (2010) it was seen that oral Chloroquine was prescribed to near about 25\% patients and Artesunate and SulfadoxinePyrimethamine combination was prescribed to $24 \%$

\begin{tabular}{|c|c|c|}
\hline Anti-malarial drug prescribed & Number & Percentage \\
\hline Chloroquine (oral) & 48 & 23.1 \\
\hline Artemether+lumefantrine & 46 & 22.1 \\
\hline $\begin{array}{l}\text { Artesunate+sulfadoxine- } \\
\text { pyrimethamine }\end{array}$ & 46 & 22.1 \\
\hline Artesunate+mefloquine & 54 & 26.0 \\
\hline Injectable artemether & 14 & 6.7 \\
\hline Total & 208 & 100.0 \\
\hline
\end{tabular}

\begin{tabular}{lcc}
\multicolumn{3}{l}{ Table 2: List of drug prescribed } \\
\hline Name of drug & Number & Percentage \\
\hline Chloroquine & 48 & 23.1 \\
Artemether & 60 & 28.8 \\
Artesunate & 100 & 48.1 \\
Lumefantrine & 46 & 22.1 \\
Sulfadoxine & 46 & 22.1 \\
Pyrimethamine & 46 & 22.1 \\
Mefloquine & 54 & 25.9 \\
Primaquine & 118 & 56.7 \\
Doxicycline & 34 & 16.3 \\
Azithromycin & 10 & 4.8 \\
Cefixime & 14 & 6.7 \\
Levofloxacin & 14 & 6.7 \\
Amoxicillin & 18 & 8.7 \\
Proton pump inhibitor & 136 & 65.4 \\
H blocker & 52 & 25.0 \\
Vitamin B complex & 28 & 13.5 \\
Total number of drugs prescribed & 824 & 100 \\
\hline So, average number of drugs per patient was $824 / 208=3.96$ & \\
& &
\end{tabular}


patients. ${ }^{2}$ In a study by Faheem Mubeen et al (2012) it is seen that Artesunate and Sulfadoxine-Pyrimethamine were prescribed to $46.1 \%$ patients having single infection with Plasmodium falciparum. ${ }^{3}$ With gradual development of Chloroquine resistant P. falciparum parasite, the prescription habit of the practitioners is changing but the present study has highlighted that Chloroquine has been prescribed to a sizable proportion of patients $(22.9 \%)$.

Chedi BAZ et al (2010) have found that average number of drugs per prescription for malaria treatment was 3.65. ${ }^{2}$ Hogerzeil et al, (1993) have found that average number of drugs per prescription was 1.3-2.2. ${ }^{4}$ Isah et al (2001) have done a study in Nigeria and Owusu-Daaku et al, (2004) have done a study in Ghana: both have found that average drug per prescription was near about 4., ${ }^{5,6}$ According to World Health Organization guideline of rational use of medicine, the average number of drug per prescription should be minimum (1.6-1.8), (Isah et al, 2004) but poly-pharmacy is seen commonly in patients with complicated falciparum malaria. ${ }^{7}$ However in the present study the average number of drugs per prescription was near about 4. It is true that often falciparum malaria becomes complicated and to prevent complication Artesunate combination therapy is essential. To combat with the complicated condition as

\begin{tabular}{|c|c|c|c|}
\hline Name of drug & $\begin{array}{l}\text { Number of } \\
\text { patients }\end{array}$ & $\begin{array}{l}\text { Number } \\
\text { prescribed by } \\
\text { generic name }\end{array}$ & Percentage \\
\hline Chloroquine & 48 & 11 & 22.9 \\
\hline Artemether & 60 & 7 & 11.7 \\
\hline Artesunate & 100 & 15 & 15.0 \\
\hline Lumefantrine & 46 & 7 & 15.2 \\
\hline Sulfadoxine & 46 & 8 & 17.4 \\
\hline Pyrimethamine & 46 & 8 & 17.4 \\
\hline Mefloquine & 54 & 7 & 13.0 \\
\hline Primaquine & 118 & 9 & 7.6 \\
\hline Doxicycline & 34 & 3 & 8.8 \\
\hline Azithromycin & 10 & 0 & 0.0 \\
\hline Cefixime & 14 & 5 & 35.7 \\
\hline Levofloxacin & 14 & 3 & 21.4 \\
\hline Amoxicillin & 18 & 5 & 27.8 \\
\hline Proton pump inhibitor & 136 & 22 & 16.2 \\
\hline $\mathrm{H}_{2}$ blocker & 52 & 34 & 65.4 \\
\hline Vitamin B complex & 28 & 1 & 3.6 \\
\hline Total & 824 & 139 & 16.9 \\
\hline
\end{tabular}

Table 4: Pattern of prescription of antibiotics

\begin{tabular}{lcc}
\hline Name of antibiotic & Number of patients & Percentage \\
\hline Doxycycline & 34 & 16.3 \\
Azithromycin & 10 & 4.8 \\
Cefixime & 14 & 6.7 \\
Levofloxacin & 14 & 6.7 \\
Amoxicillin & 18 & 8.7 \\
Total & 90 & 43.3 \\
\hline
\end{tabular}

well as to prevent complication the average number of drugs prescribed cannot be considered irrational in the present context.

Chedi BAZ et al (2010) have found that more than 40\% drugs were prescribed in generic name. ${ }^{2}$ In other studies also the prescription by generic name was more than $50 \%$ (Isah et al, 2001) and (Owusu-Daaku et al, 2004). ${ }^{5,6}$ WHO suggests $100 \%$ prescription of drugs in generic name. Prescription pattern in generic name is lacking in the present study (only 16.9\%). The use of brand name has often negative impact on the treatment as the cost of treatment increases.

Chedi BAZ et al (2010) found that 65\% prescriptions of malaria had an antibiotic and near about $80 \%$ drugs were prescribed from essential drug list. ${ }^{2}$ However, Isah et al (2001) have found that 96-98\% drugs were prescribed from essential drug list. ${ }^{5}$ In the present study $43 \%$ prescriptions had antibiotic co-prescribed; out of which $16.3 \%$ was Doxycycline which has anti-malarial effect itself (Table 4). Near about 85\% drugs were from essential drug list (Table 5). Only Artemether, Lumefantrine and Levofloxacin are not in essential drug list; but Artemether and Lumefantrine has anti-malarial effect and so these prescriptions are not irrational. Only Levofloxacin does not have any direct effect for the treatment of falciparum

\begin{tabular}{lcc} 
Table 5: Drug prescription from essential drug list \\
\hline Name of drug & $\begin{array}{c}\text { Inclusion in } \\
\text { essential drug list }\end{array}$ & Number \\
\hline Chloroquine & Yes & 48 \\
Artemether & No & 60 \\
Artesunate & Yes & 100 \\
Lumefantrine & No & 46 \\
Sulfadoxine & Yes & 46 \\
Pyrimethamine & Yes & 46 \\
Mefloquine & Yes & 54 \\
Primaquine & Yes & 118 \\
Doxicycline & Yes & 34 \\
Azithromycin & Yes & 10 \\
Cefixime & Yes & 14 \\
Levofloxacin & No & 14 \\
Amoxicillin & Yes & 18 \\
Proton pump inhibitor & Yes & 136 \\
H blocker & Yes & 52 \\
Vitamin B complex & Yes & 28 \\
\hline
\end{tabular}

So, out of total 824 drugs prescribed, 704 (85.4\%) were from essential drug list or formulary

\begin{tabular}{lc} 
Table 6: Average drug cost per patient \\
\hline Total number of patients treated & 208 \\
Total cost of medicine & Rs. $58656 /-$ \\
Average drug cost per patient ( \pm S.D.) & Rs. 282/- $( \pm$ Rs. 229/-) \\
Maximum drug cost for a patient & Rs. $1750 /-$ \\
Minimum drug cost for a patient & Rs. $55 /-$ \\
Median of drug cost per patient & Rs. $400 /-$ \\
\hline
\end{tabular}

Asian Journal of Medical Sciences | Jul-Aug 2016 | Vol 7 | Issue 4 
malaria; it was prescribed for prevention of other secondary infection.

\section{CONCLUSION}

Government of India has issued guideline that in Chloroquine resistant areas, Artemisinin combination therapy (ACT) should be given. The present study has highlighted that Chloroquine therapy for falciparum malaria treatment is not obsolete; rather more than $20 \%$ patients were treated with chloroquine. One positive finding is that the use of injectable drug is very minimum. Most of the patients were treated with oral drugs. Guideline also says that injectable drugs should be reserved for serious and complicated cases of falciparum malaria only. The age old drug quinine was not prescribed to a single patient. This indicates that the use of ACT is getting popularized. Doxycyline has anti-malarial property and so it was the most commonly prescribed antibiotic among the study subjects. Most of the drug (85.4\%) prescription from essential drug list indicates rationality of prescription.

Finally it can be said that drug prescription pattern varies widely based on geographical location, prescriber and patient characteristics and many other factors. The present study has shown a snapshot of drug prescription pattern for the treatment of falciparum malaria in a medical college in Eastern India for a period of two years. This gives us an idea about the commonly used drugs and prescription habit of physician for treating this condition. But it keeps on changing from time to time. New and new anti-malarials are being developed and these are getting popularized among practicing physicians. So, continuous monitoring on this in multi-centric study can have a bigger impact in long run.

\section{REFERENCES}

1. Introduction to Drug Utilization Research. World Health Organization. Oslo, Norway. 2003. p 1-3.

2. Chedi BAZ, Abdu-aguye I and Kwanashie HO. Interventional studies of anti-malarial drug utilization in public health facilities in Kano, Nigeria. Bajopas 2010; 3(1): 49-53.

3. Mubeen F, Pandey DK and Jaheer M. Drug Utilization Pattern of Antimalarial Drugs at a tertiary care hospital: A Retrospective study. IJMPS 2012; 3(5): 01-05.

4. Hogerzeil HV, Bimo, Ross-Degnan D, Laing RO, Oforie-Adjei D, Santoso B, et al. Field test for rational drug use in twelve developing countries. Lancet 1993; 342: 1408-1410.

5. Isah EC, Isah $\mathrm{AO}$, Ohaju-Obodo JO and Okojie OH. Prescribing practices in public health facilities in Edo and Delta states of Nigeria: a field experience with WHO prescribing indicators. West African Journal of Pharmacology and Drug Research 2001; 17: 22-28.

6. Owusu-Daaku FTK and Sablah J. The essential drug list and drug use indicators at two University Hospitals: KNUST and Legon, Ghana. West African Journal of Pharmacy 2004; 18:53-57.

7. Isah AO, Ross-Degnan D, Quick, JD, Laing R and Mabadeje AFB. The development of standard values for the WHO drug use prescribing indicators. World Health Organization. 2004, Geneva.

Authors Contribution:

PPD - Concept of the study, Study design, literature review, data collection, data analysis, manuscript preparation, Manuscript editing and Final

Approval; AP - Concept of the study, interpretation, critical appraisal of manuscript; CP- Concept of the study, interpretation, critical appraisal; ASC - Data

Acquisition; PP - Conceptualization, Literature review, data analysis, data interpretation, critical appraisal of manuscript.

Source of Support: Nil. Conflict of Interest: None. 